\title{
Peptide receptor radionuclide therapy in a patient with disabling non-functioning pituitary adenoma
}

\author{
Jan Komor · Jean Claude Reubi - Emanuel R. Christ
}

Published online: 6 June 2013

(c) Springer Science+Business Media New York 2013

\begin{abstract}
Non-functioning pituitary adenoma (NFPA) with higher proliferation index (WHO II) are often a therapeutical challenge. Low somatostatin receptor expression in these tumors usually prevents a treatment with somatostatin analogs. In 1996, a 55-year-old patient was referred due to right-sided headache. A pituitary macroadenoma with infiltration into the right cavernous sinus was diagnosed. There was no visual field deficit and the clinical and biochemical work up was consistent with a NFPA. The patient underwent transsphenoidal surgery. Residual adenoma remained in the right cavernous sinus. Histologically, a null-cell adenoma with a high proliferation index was documented (MIB-1: $11.6 \%$, WHO II). Somatostatin receptor autoradiography was performed in the surgical specimen showing a homogenous expression of sst $_{2}$ receptors. Radiosurgery was completed with stable disease for 8 years. In 2004, the patient was diagnosed with an incomplete palsy of the right oculomotorius nerve and a significant increase in the volume of the adenoma in the right cavernous sinus. After a positive Octreoscan ${ }^{\circledR}$ the patient consented to an experimental therapy approach using Lutetium DOTATOC $(3 \times 200 \mathrm{mCi})$. The palsy of the oculomotorius nerve improved and remained stable until today (March 2013), the follow-up MRI scans
\end{abstract}

\section{J. Komor}

Bühlstrasse 5, 3012 Bern, Switzerland

J. C. Reubi

Cell Biology and Experimental Cancer Research,

Institute of Pathology, University of Bern, Bern, Switzerland

E. R. Christ ( $\square)$

Division of Endocrinology, Diabetology and Clinical Nutrition, University Hospital of Bern, Inselspital, 3010 Bern, Switzerland

e-mail: emanuel.christ@insel.ch demonstrated stable disease. This is the first case of a patient with a NFPA (WHO II) in whom PRRT successfully improved the local complications of the tumor for more than 8 years after ineffective surgery and gamma knife therapy. The determination of $\mathrm{sst}_{2}$ in vitro using autoradiography and in vivo by Octreoscan was instrumental to administer this therapy in a challenging situation.

Keywords Non-functioning pituitary adenoma WHO II · Peptide receptor radionuclide therapy - Octreoscan .

Nervus oculomotorius - Somatostatin receptors

\section{Introduction}

Peptide receptor radionuclide therapy (PRRT) with radiolabeled somatostatin analogues (i.e. 90Y-DOTATOC, ${ }^{177}$ Lu-DOTATATE) has been shown to be an effective tool in treating metastasized gut neuroendocrine tumors (NET) $[1,2]$. These gut NET are characterized by the presence of a high number of somatostatin receptor subtype $2\left(\mathrm{sst}_{2}\right)$ that are distributed on the tumor cell membranes [3], and are the molecular basis for therapy with somatostatin analogs. Tumoral $\mathrm{sst}_{2}$ can be detected not only in vivo by an Octreoscan ${ }^{\odot}[4]$ but also in vitro by receptor autoradiography [5] or recently by immunohistochemistry [6].

In pituitary GH- [7], TSH- [8, 9] and ACTH-secreting tumors [10], PRRT with radiolabeled somatostatin analogs is rarely chosen. Instead, non-radioactive somatostatin analogues (octreotide, lanreotide) are established in inhibiting hormone secretion and-in part-growth of these tumors, the effectiveness of the therapy being dependent on the receptor expression. In non-functioning pituitary adenoma (NFPA), the therapy is primarily surgical rather than octreotide or PRRT, in particular since the somatostatin 

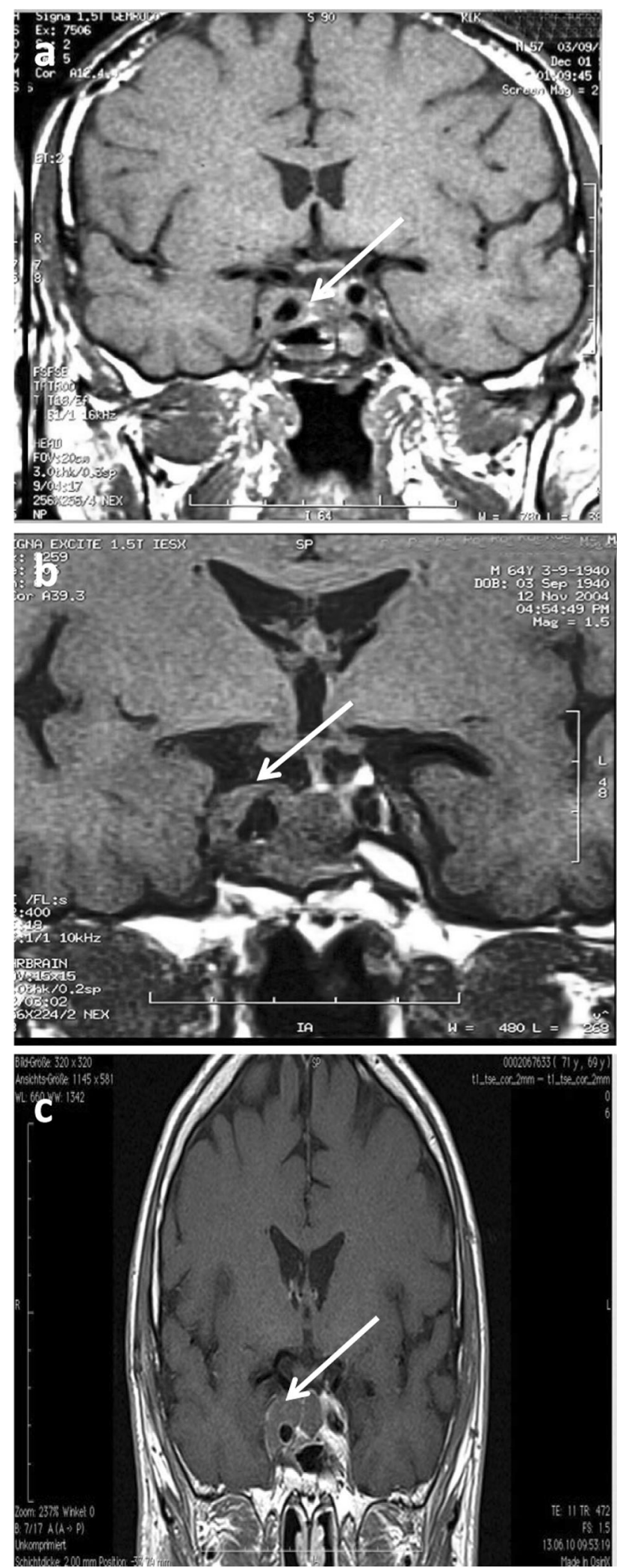

receptors of the $\mathrm{sst}_{2}$ subtype are much less frequently expressed [3, 11, 12]. In pituitary NFPA with higher proliferation index (WHO II), a type of tumor which is often a
4 Fig. 1 Contrast coronal magnetic resonance imaging (T1WI) after transsphenoidal surgery in 1996 (a) and at the time of N. oculomotorius palsy in 2004 (b). Following surgery there is residual tumor within the sinus cavernosus right (a arrow) and the remaining intact pituitary gland is on the left. During follow-up residual tumor within the sinus cavernosus right increases in size resulting in N. oculomotorius palsy (b arrow). Last magnetic resonance imaging in 2011 showing stable residual mass in the right sinus cavernosus (c arrow)

therapeutical challenge, data on $\mathrm{sst}_{2}$ status are virtually missing.

In this paper we report for the first time of a patient with a NFPA WHO II and severe ocular manifestations, who had a tumor with high density of $\mathrm{sst}_{2}$ which could be brought under control for over 8 years, after a PRRT with radiolabeled somatostatin analogs was performed.

\section{Case report}

In 1996, a 56 years old patient was referred for brain MRI scan due to new severe right-sided headache. A pituitary macroadenoma with infiltration into the right cavernous sinus and extending to the optic chiasm was diagnosed. There was no visual field deficit at the time and the clinical and biochemical work up was consistent with a NFPA without pituitary deficiencies.

In October 1996 the patient underwent successful transsphenoidal surgery. Residual adenoma remained in the right cavernous sinus which was impossible to remove (Fig. 1a). A fat pad was introduced between the intact pituitary gland on the left side and the right cavernous sinus. This allowed for protecting the functioning pituitary gland from the planned radiotherapy. Histologically, a null-cell adenoma with a high proliferation index was documented (MIB-1: $11.6 \%$ ) consistent with a pituitary adenoma WHO II. Additionally, at that early stage of disease, somatostatin receptor autoradiography $\left({ }^{125} \mathrm{I}_{\mathrm{T}} \mathrm{Tyr}^{3}\right.$-Octreotide) was performed that showed a homogenous expression of $\mathrm{sst}_{2}$ receptors in high density in the adenoma (Fig. 2A).

In November 1996 radiosurgery was performed for the residual tumor using gamma knife (dose $50 \mathrm{~Gy}$ ). No pituitary insufficiencies ensued and visual fields and opthalmological examination were normal.

Follow-up MRI scans in 1997 and 1999 showed stable residual adenoma, in 2001 even a reduction of the residual tumor was detected and the patient renounced further neuroradiological follow-up.

In 2004, the patient was investigated following an acute decrease in visual acuity with additional double images in the horizontal axis. In addition, incomplete ptosis of the right eyelid and right eye mydriasis was evident suggesting oculomotor nerve palsy (Fig. 3). MRI scan demonstrated a significant increase in the volume of the adenoma in the 


\section{A}
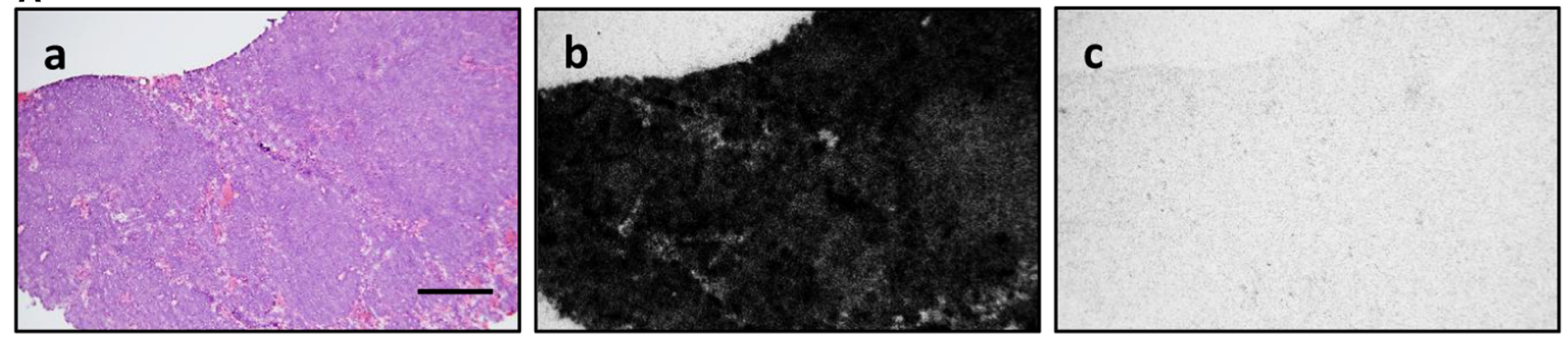

B

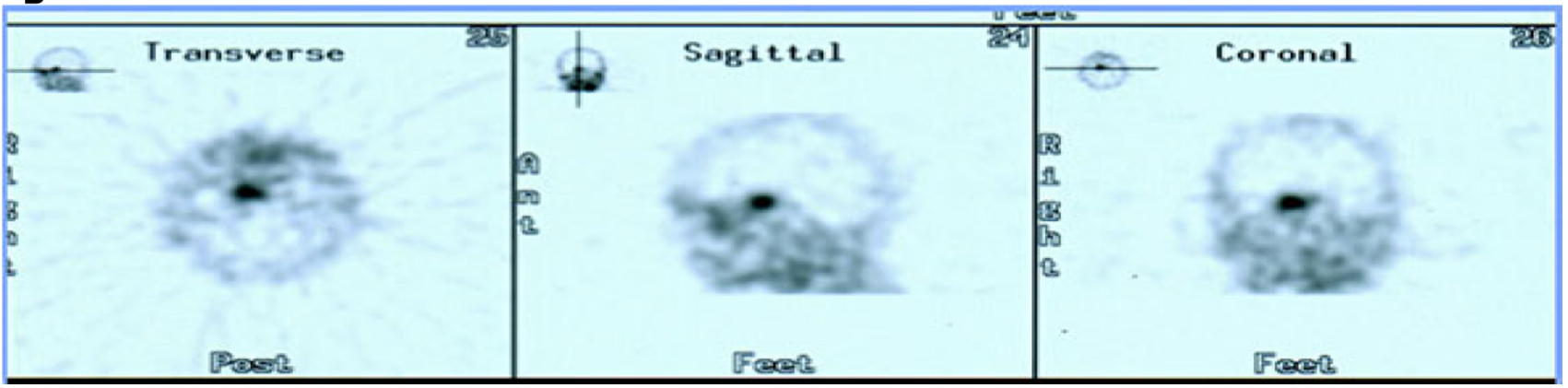

Fig. $2 \mathrm{~A} \mathrm{sst}_{2}$ receptor determinations in vitro in the pituitary adenoma of the patient. $a$ Hematoxylin-eosin-stained tumor tissue. $b$ Autoradiogram showing total binding of ${ }^{125} \mathrm{I}^{-\mathrm{Tyr}^{3}}$-octreotide in the pituitary adenoma. The whole tumor is strongly positive.

right cavernous sinus (Fig. 1b) indicating that the opthalmological symptoms were related to a progression of the adenoma. A second surgical intervention was impossible and an additional radiotherapy carried a significant risk for side effects. Due to the known high expression of $\mathrm{sst}_{2}$ in the adenoma the patient consented to an experimental therapy approach using PPRT with Lutetium DOTATOC andafter a positive Octreoscan ${ }^{\text {TM }}$ (Fig. 2B)—PRRT was successfully administered in $2005(3 \times 200 \mathrm{mCi})$. The palsy of the oculomotorius nerve improved, the follow-up MRI scans demonstrated stable disease up to now (March 2013) and the pituitary function remained intact.

\section{Discussion}

To our knowledge this is the first case of a patient with a NFPA (WHO II) in whom PRRT successfully stabilized and improved the local complications of the tumor after ineffective surgery and gamma knife therapy. The determination of sst $_{2}$ in vitro using autoradiography and in vivo by Octreoscan was instrumental to administer this experimental therapy in a clinically challenging situation.

While the therapeutical effect of somatostatin analogues in controlling autonomous endocrine secretion and inducing GH-adenoma shrinking is well established [7, 9, 10, 13, 14] the effectiveness of somatostatin analogues on local c Autoradiogram showing nonspecific binding of ${ }^{125} \mathrm{I}^{-\mathrm{Tyr}^{3}}$-octreotide in the presence of cold octreotide $\left(10^{-6} \mathrm{M}\right)$. B Octreoscan ${ }^{\circledR}$ in a patient with a non-functioning pituitary adenoma (WHO II) showing intense uptake in the region of the pituitary

tumor control in patients with NFPA, is less evident: not only is the $\mathrm{sst}_{2}$ expression much lower than in other pituitary tumors $[3,11]$ but also the octreotide effect is much more difficult to assess due to the lack of a reliable hormonal parameter. Moreover, surgery and-if neededradiotherapy is usually capable to control the disease in the vast majority of patients. Several uncontrolled short-term studies (3-12 months) indicate that somatostatin analogues may stabilize residual tumor size in NFPA but do not induce significant tumor shrinkage [15-18]. One recent prospective study over 3 years assessed the effect of octreotide LAR on progression in NFPA with postoperatively residual tumor and suggest an effect on stabilization but not on shrinkage [19].

PRRT - a targeted radiotherapy - results in a stabilization of the disease with regard to secretion (if present) and growth $[1,2]$ in metastasized gut neuroendocrine tumors $[1,2]$ that are well known to contain sst $_{2}$ in high density. Because PRRT in these tumors is known to induce persisting side-effects (renal failure, bone marrow toxicity [2]), the indication for therapy has to be carefully discussed on the basis of somatostatin receptor status. No PRRT study with long-term follow-up in NFPA has been published. Two recent communications reported the efficacy and safety of PRRT in a patient with pituitary metastasis of a NET [20] and in a patient with a giant prolactin secreting tumor resistant to dopamine-agonists [21], but the follow-up 

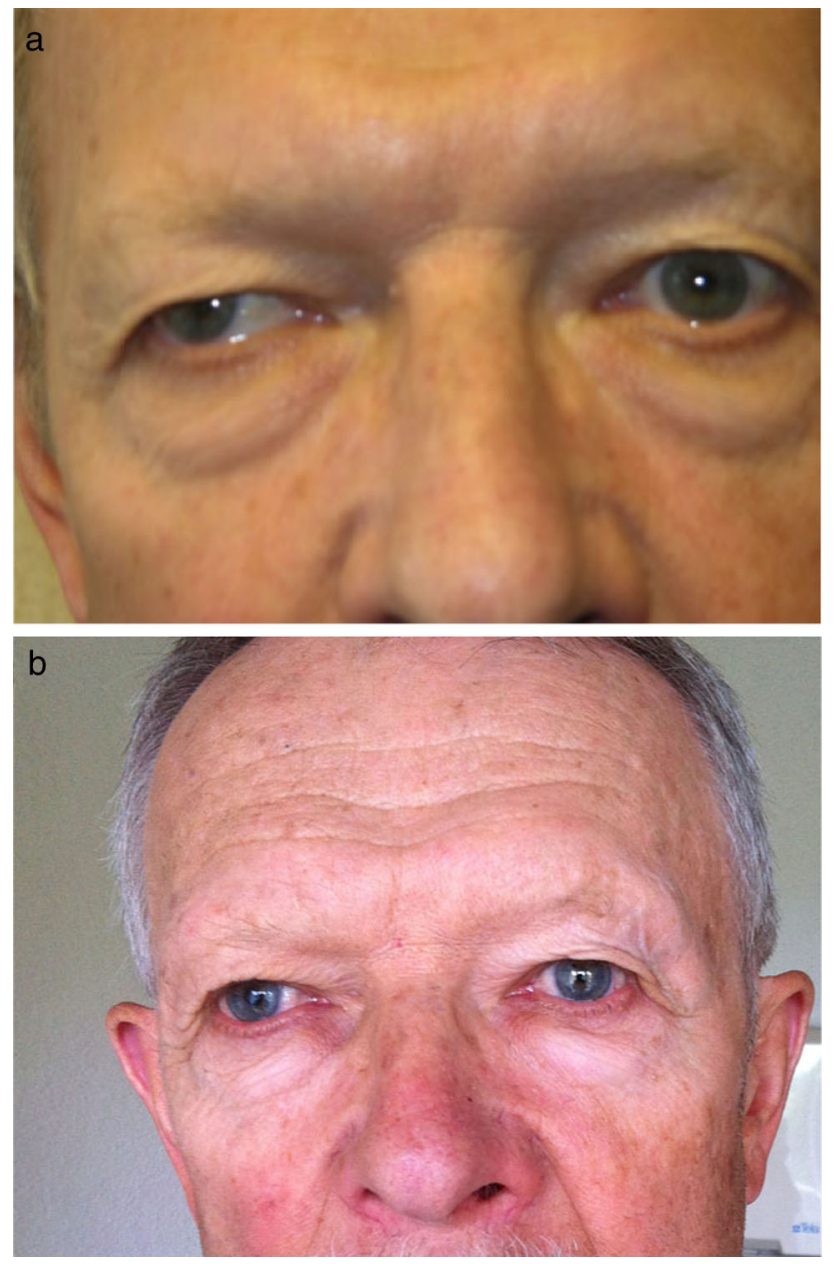

Fig. 3 Double images in the horizontal axis, incomplete ptosis and right eye mydriasis suggesting oculomotor nerve palsy (a). After PRRT significant improvement of oculomotor nerve palsy can be documented that persist until the last visit in 2012 (b)

of the two cases was less than 2 years and the somatostatin receptor profile had not been analyzed in vitro before therapy.

The present tumor presented on one hand with a high density of sst $_{2}$ and, on histology, with an elevated mitotic index consisting with an atypical pituitary adenoma (WHO II). In the German pituitary registry atypical adenoma account for $2.7 \%$ of all registered pituitary neoplasms and the null cell adenomas were amongst the most frequent type [22]. Some evidence suggests that atypical adenomas have a poorer prognosis that may be related to a higher degree of local invasiveness, larger size and accelerated growth as shown in the present case. In such challenging cases an additional therapeutical strategy based on targeted radiotherapy may be helpful in controlling the disease.

Personalized medicine is a new therapeutical strategy in oncology that considers molecular targets of the tumors into the treatment regime [23]. The present case may impressively support the concept that personalized medicine should be discussed in endocrine patients, at least in those who present with a challenging course of their disease such as NFPA (WHO II). A prerequisite is the availability of a simple way to reliably measure somatostatin receptors in vitro within the tumor sample in order to have a molecular rationale for PRRT. Eight years ago the rather complex and costly receptor autoradiography technique was used to analyze sst receptors in this patient because no satisfactory alternative existed. An sst ${ }_{2}$ antibody has recently been developed that can, alternatively, be employed in future to detect $\mathrm{sst}_{2}$ immunohistochemically on formalin-fixed tissue [6]. This will simplify the therapeutical strategy in challenging cases and may contribute to a personalized medicine in endocrinology.

Acknowledgments We are grateful to the patient who allowed us to publish his case.

Conflict of interest The authors declare that they have no conflict of interest.

Ethical standards The experiments comply with the current laws of Switzerland.

\section{References}

1. Kwekkeboom DJ, de Herder WW, Krenning EP (2011) Somatostatin receptor-targeted radionuclide therapy in patients with gastroenteropancreatic neuroendocrine tumors. Endocrinol Metab Clin North Am 40:173-185, ix

2. Imhof A, Brunner P, Marincek N, Briel M, Schindler C, Rasch H, Macke HR, Rochlitz C, Muller-Brand J, Walter MA (2011) Response, survival, and long-term toxicity after therapy with the radiolabeled somatostatin analogue [90Y-DOTA]-TOC in metastasized neuroendocrine cancers. J Clin Oncol 29:2416-2423

3. Reubi JC, Waser B, Schaer JC, Laissue JA (2001) Somatostatin receptor sst1-sst5 expression in normal and neoplastic human tissues using receptor autoradiography with subtype-selective ligands. Eur J Nucl Med 28:836-846

4. Kwekkeboom DJ, Krenning EP, de Jong M (2000) Peptide receptor imaging and therapy. J Nucl Med 41:1704-1713

5. Reubi JC, Kvols LK, Waser B, Nagorney D, Heitz PU, Charboneau JW, Reading CC, Moertel C (1990) Detection of somatostatin receptors in surgical and percutaneous needle biopsy samples of carcinoids and islet cell carcinomas. Cancer Res 50:5969-5977

6. Korner M, Waser B, Schonbrunn A, Perren A, Reubi JC (2012) Somatostatin receptors subtype $2 \mathrm{~A}$ immunohistochemistry using a new monoclonal antibody selects tumors suitable for in vivo somatostatin receptor targeting. Am J Surg Pathol 36:242-252

7. Colao A, Auriemma RS, Galdiero M, Lombardi G, Pivonello R (2009) Effects of initial therapy for five years with somatostatin analogs for acromegaly on growth hormone and insulin-like growth factor-I levels, tumor shrinkage, and cardiovascular disease: a prospective study. J Clin Endocrinol Metab 94:3746-3756

8. Kuhn JM, Arlot S, Lefebvre H, Caron P, Cortet-Rudelli C, Archambaud F, Chanson P, Tabarin A, Goth MI, Blumberg J, Catus F, Ispas S, Beck-Peccoz P (2000) Evaluation of the treatment of thyrotropin-secreting pituitary adenomas with a slow release 
formulation of the somatostatin analog lanreotide. J Clin Endocrinol Metab 85:1487-1491

9. Beck-Peccoz P, Brucker-Davis F, Persani L, Smallridge RC, Weintraub BD (1996) Thyrotropin-secreting pituitary tumors. Endocr Rev 17:610-638

10. Colao A, Petersenn S, Newell-Price J, Findling JW, Gu F, Maldonado M, Schoenherr U, Mills D, Salgado LR, Biller BM (2012) A 12-month phase 3 study of pasireotide in Cushing's disease. N Engl J Med 366:914-924

11. Lupp A, Nagel F, Doll C, Rocken C, Evert M, Mawrin C, Saeger W, Schulz S (2012) Reassessment of sst3 somatostatin receptor expression in human normal and neoplastic tissues using the novel rabbit monoclonal antibody UMB-5. Neuroendocrinology 96:301-310

12. Taboada GF, Luque RM, Bastos W, Guimaraes RF, Marcondes JB, Chimelli LM, Fontes R, Mata PJ, Filho PN, Carvalho DP, Kineman RD, Gadelha MR (2007) Quantitative analysis of somatostatin receptor subtype (SSTR1-5) gene expression levels in somatotropinomas and non-functioning pituitary adenomas. Eur J Endocrinol 156:65-74

13. Culler MD, Oberg K, Arnold R, Krenning EP, Sevilla I, Diaz JA (2011) Somatostatin analogs for the treatment of neuroendocrine tumors. Cancer Metastasis Rev 30(Suppl 1):9-17

14. Grasso LF, Pivonello R, Colao A (2012) Somatostatin analogs as a first-line treatment in acromegaly: when is it appropriate? Curr Opin Endocrinol Diabetes Obes 19:288-294

15. de Bruin TWA, Kwekkeboom DJ, van'T Verlaat JW, Reubi JC, Krenning EP, Lamberts SWJ, Croughs RJM (1992) Clinically nonfunctioning pituitary adenoma and octreotide response to long term high dose treatment, and studies in vitro. J Clin Endocrinol Metab 75:1310-1317

16. Plockinger U, Reichel M, Fett U, Saeger W, Quabbe HJ (1994) Preoperative octreotide treatment of growth hormone-secreting and clinically nonfunctioning pituitary macroadenomas: effect on tumor volume and lack of correlation with immunohistochemistry and somatostatin receptor scintigraphy. J Clin Endocrinol Metab 79:1416-1423

17. Warnet A, Harris AG, Renard E, Martin D, James-Deidier A, Chaumet-Riffaud P (1997) A prospective multicenter trial of octreotide in 24 patients with visual defects caused by nonfunctioning and gonadotropin-secreting pituitary adenomas. French Multicenter Octreotide Study Group. Neurosurgery 41:786-795; discussion 796-797

18. Gasperi M, Petrini L, Pilosu R, Nardi M, Marcello A, Mastio F, Bartalena L, Martino E (1993) Octreotide treatment does not affect the size of most non-functioning pituitary adenomas. J Endocrinol Invest 16:541-543

19. Fusco A, Lugli F, Sacco E, Tilaro L, Bianchi A, Angelini F, Tofani A, Barini A, Lauriola L, Maira G, Pontecorvi A, de Marinis L (2011) Efficacy of the combined cabergoline and octreotide treatment in a case of a dopamine-agonist resistant macroprolactinoma. Pituitary 14:351-357

20. Goglia U, Ferone D, Sidoti M, Spaziante R, Dadati P, Ravetti JL, Villa G, Bodei L, Paganelli G, Minuto F, Giusti M (2008) Treatment of a pituitary metastasis from a neuroendocrine tumour: case report and literature review. Pituitary 11:93-102

21. Baldari S, Ferrau F, Alafaci C, Herberg A, Granata F, Militano V, Salpietro FM, Trimarchi F, Cannavo S (2012) First demonstration of the effectiveness of peptide receptor radionuclide therapy (PRRT) with 111In-DTPA-octreotide in a giant PRL-secreting pituitary adenoma resistant to conventional treatment. Pituitary 15(Suppl 1):57-60

22. Saeger W, Ludecke DK, Buchfelder M, Fahlbusch R, Quabbe HJ, Petersenn S (2007) Pathohistological classification of pituitary tumors: 10 years of experience with the German Pituitary Tumor Registry. Eur J Endocrinol 156:203-216

23. Haura EB (2012) From modules to medicine: how modular domains and their associated networks can enable personalized medicine. FEBS Lett 586:2580-2585 